\title{
Estado, contrarreforma e as políticas de saúde e saúde mental no Brasil
}

\author{
State, counter-reforms and health and mental health policies in Brazil
}

Lara Lisboa FARIAS*

https://orcid.org/0000-0001-75.54-6671

Resumo: O artigo realiza uma análise qualitativa das ações de desmonte do Estado brasileiro no que se refere à área da saúde, e ao campo da saúde mental, álcool e outras drogas, com um levantamento bibliográfico, a fim de identificar elementos transformadores das políticas, a partir de cinco normativas recém-aprovadas pelo governo federal (EC 95/2016; Portaria CIT 3.588/2017; Portaria Conad 1/2018 e Resolução CIT 32/2017); e o PL 7.419/2006, que foi retomado; além de discursos em entrevistas de representantes do Estado; e da Nota Técnica 11/2019, do Ministério da Saúde. Na análise, relaciona-se teoricamente com a discussão das categorias centrais levantadas: Estado, Política Social; Contrarreforma, partindo de referenciais consolidados. Considera-se o pressuposto de que há, atualmente, um movimento contrarreformista, sob a ótica conservadora, nas políticas de saúde e saúde mental. O artigo é dividido em quatro tópicos. Na primeira parte, faz-se uma análise das características e dos fundamentos das políticas sociais no Estado capitalista, bem como das funções do Estado para a reprodução do capitalismo, com breve resgate da concepção de Estado, em Poulantzas (1985). No segundo tópico, adentra-se, mais especificamente, na política de saúde, explicitando as contrarreformas do Estado nesse setor. Na terceira parte, dá-se enfoque à política de saúde mental, álcool e outras drogas, áreas em que as contrarreformas vêm se instituindo de forma mais drástica. Por fim, na quarta parte, conclui-se a análise, confirmando a afirmativa de que as políticas em questão vêm sendo desmontadas pelo Estado, segundo uma lógica que classifica a saúde como mercadoria e trata a saúde mental como objeto de filantropia e violação de direitos humanos.

Palavras-chave: Estado; Política Social; Contrarreforma; Neoconservadorismo; SUS; Saúde Mental, Álcool e Drogas.

Abstract: This study conducts a qualitative analysis of the dismantling actions of the Brazilian State in the fields of health and mental health, alcohol and other drugs. In order to achieve the objectives a bibliographical survey was carried out to identify the transforming elements of the policies based on five regulations recently approved by the federal government (EC 95/2016, Ordinance CIT 3.588/2017, Ordinance CONAD1/2018 and Resolution CIT 32/2017), a draft law that was adopted (PL 7.419/2006), and interviews of representatives of the State and Technical Note 11/2019 of the Ministry of Health. The analysis seeks to relate theoretically to the discussion of the central categories raised: State, Social Policy; Counterreform, based on consolidated benchmarks. It assumes that there is currently a counter-reformist movement, with a conservative viewpoint, in health and mental health policies. The article is divided into four topics. In the first part, an analysis is made of the characteristics and foundations of social policies in

\footnotetext{
* Assistente Social.Universidade de Brasília (UnB). Mestranda do Programa de Pós-graduação em Política Social (PPGPS) da Universidade de Brasília (UnB). Campus Darcy Ribeiro, Asa Norte, Brasília (DF), CEP.: 70910-900. E-mail: <lisboalara@hotmail.com>.

Este artigo é resultado de reflexões e discussões feitas na disciplina de Seguridade Social - Saúde do PPGPS-UnB, bem como compõe o projeto de dissertação de mestrado da autora. Creative Commons Atribuição 4.0 Internacional (https://creativecommons.org/licenses/by/4.o/deed.pt_BR), que permite copiar e redistribuir o material em qualquer suporte ou formato, bem como adaptar, transformar e criar a partir deste material para qualquer fim, mesmo que comercial. O licenciante não pode revogar estes direitos desde que você respeite os termos da licença.
}

Argum., Vitória, v. 11, n. 3, p. 47-66, set./dez. 2019. | ISSN 2176-9575 
the capitalist State, as well as of the functions of the State for the reproduction of capitalism, making a brief revisit to the concept of State in Poulantzas (1985). In the second, it focuses, more specifically, on the health policy itself, explaining the counter-reforms of the State in this sector. The third part focuses on the politics of mental health, alcohol and other drugs, where counter-reforms have been deployed more drastically. Lastly, the fourth part concludes the analysis, confirming the assertion that the State has detrimentally dismantled previous policies, following a logic that classifies health as a commodity and treats mental health as an object of philanthropy and violates human rights.

Key words: State; Social Policy; Counter-reform; Neoconservatism; SUS, Mental Health, Alcohol and Drugs.

Submetido em: 10/12/2018. Revisado em: 24/04/2019. Aceito em: 10/05/2019.

\section{Introdução}

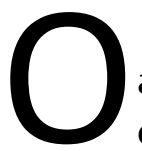

contexto brasileiro atual, que é marcado pela contrarreforma do Estado, tem afetado a política de saúde e o campo de saúde mental, álcool e outras drogas, de maneira agressiva. Os avanços alcançados desde as Reformas Sanitária e Psiquiátrica, propostas na década de 1970, e com a consolidação do Sistema Único de Saúde (SUS), que partiram de uma perspectiva de direitos, de saúde universal e da luta antimanicomial, estão sendo, desde o governo Dilma, e, mais incisivamente, no decorrer do governo Temer, desmontados por alterações nas legislações sobre as temáticas. São modificações que vêm ganhando amplo espaço, também, no governo de Jair Bolsonaro, iniciado em 2019.

A compreensão desses fatos exige apreender as políticas sociais como totalidade e ainda parte das histórias política, social e econômica, que estão em constante movimento, visto que, a depender da conjuntura do País, tais políticas podem ter características distintas. A política de saúde brasileira, por sua vez, está imersa em um contexto de avanço da nova direita, que é caracterizada pela junção do neoliberalismo econômico com o neoconservadorismo social e político (PEREIRA, 2016). Nesse sentido, existe uma tendência de desmantelamento de direitos e de retorno às práticas neoconservadoras, que moralizam e criminalizam a questão social ${ }^{1}$, de um lado, e de financeirização e mercadorização, de outro, numa lógica de desresponsabilização do Estado, no que se refere à proteção social aos mais pobres.

Nesse cenário, é fato que se tem “[...] assistido na evolução do capitalismo o predomínio da política econômica sobre a política social [...]" (VIEIRA, 2007, p. 144), ainda que uma esteja condicionada à outra. No âmbito da saúde, essa afirmação é cada vez mais concretizada. Há uma ofensiva neoliberal em curso, pela oferta da cobertura universal de saúde, que caminha ao lado de uma ofensiva neoconservadora, por meio de um ideário moralizante e criminalizador, que visa a retroceder à perspectiva manicomial e filantrópica, no campo da saúde mental, álcool e outras drogas.

Um exemplo concreto do predomínio da política econômica em detrimento da social é o ajuste fiscal engendrado pelo governo federal (EC 95/2016), que faz cortes extremos e

\footnotetext{
1 "Questão social não é senão as expressões do processo de formação e desenvolvimento da classe operária e de seu ingresso no cenário político da sociedade [...] É a manifestação, no cotidiano da vida social, da contradição entre o proletariado e a burguesia, a qual passa a exigir outros tipos de intervenção, mais além da caridade e repressão" (IAMAMOTO; CARVALHO, 1983, p.77).
}

Argum., Vitória, v. 11, n. 3, p. 47-66, set./dez. 2019. | ISSN 2176-9575 
interfere diretamente na execução das políticas sociais. A emenda congela o investimento na saúde, por exemplo, em 20 anos, corroborando o sucateamento dos serviços e o desmonte da perspectiva de direito universal e de direito humano básico. Ainda nessa direção, percebe-se uma série de medidas tomada legalmente, que ampara o que chamamos aqui de contrarreforma. Nesse sentido, foram aprovadas legislações (Portaria 3.588/2017, da Comissão Intergestores Tripartite (CIT); Portaria 1, do Conselho Nacional sobre Drogas (Conad); e Resolução CIT 32) que reorientam a atenção no campo da saúde mental, álcool e outras drogas, numa lógica, novamente, manicomial, a mesma que compôs a pauta de luta do movimento de Reforma Psiquiátrica, momento em que foi reorientada para uma perspectiva de cidadania e sob a ótica de direitos.

Seguindo essa lógica, além das legislações já aprovadas, que serão tratadas mais à frente, no dia 27 de novembro de 2018, foi lançada, em Brasília, a frente parlamentar em favor da nova política de saúde mental, em um episódio que deixou usuários e profissionais dos serviços do lado de fora do congresso nacional, ocasião em que ainda foi utilizada a imagem dessas pessoas como apoiadoras das medidas visadas.

O documento apresentado, vale ressaltar, de iniciativa da Federação Brasileira de Hospitais, tinha cunho essencialmente contrarreformista, com impactos significativos na política, numa lógica de retrocesso, como a anexação das Comunidades Terapêuticas (CTs) como um serviço oficial da rede de atenção psicossocial; a reinserção dos hospitais psiquiátricos como serviço de atenção; a utilização da abstinência como mecanismo de enfrentamento às drogas e posição contrária à sua legalização.

Tem-se que, diante desse cenário contrarreformista, de acordo com Behring (2003), as possibilidades preventivas ficam limitadas, prevalecendo o trinômio: privatização, focalização e descentralização, essa última como mero repasse de responsabilidades para instituições privadas, com a forte presença dos hospitais psiquiátricos (popularmente chamados de manicômios), das CTs e Organizações Sociais (OS) para a gestão da saúde. Consolida-se, dessa maneira, um retrocesso social no que se refere ao direito universal à saúde como dever do Estado, e aos direitos humanos.

Para a eficaz concretização dessa lógica de desmonte, o Estado, com todo o seu aparato (não só ideológico, como também repressor e violento), é extremamente funcional e essencial ao funcionamento do sistema. Nesse sentido, este artigo parte da compreensão de Estado como uma relação, com base na teoria de Poulantzas (1985), ou seja, que está em permanente disputa e envolve a luta de classes. Atualmente, o que se percebe é o enfraquecimento das lutas sociais, devido a motivos diversos, como o medo, a insegurança, manipulação e alienação, e ascensão de uma nova direita, que vem reconfigurando as políticas sociais, numa perspectiva mercadológica e moralizante. Nesse sentido, o momento político e contrarreformista é oposto às lutas sociais dos movimentos de Reformas Psiquiátrica e Sanitária, prevalecendo o retorno de perspectivas tradicionais, que historicamente violam direitos, na área da saúde e no campo da saúde mental.

As transformações estão se dando de maneira muito rápida, pois têm sido lançados vários documentos, como os citados neste artigo; promovidos eventos de discussão 
sobre a temática, sem a participação dos usuários; e aprovados decretos que reorientam as políticas numa lógica de retrocesso. É necessário considerar, também, que, por serem mudanças recentes e rápidas, ainda não há literatura vasta que debata o assunto. Desse modo, faz-se necessário acompanhar essa contrarreforma, de modo a identificar e analisar os caminhos que vêm sendo tomados no País.

Dito isso, o objetivo deste artigo é analisar qualitativamente, com base em levantamento bibliográfico e no conteúdo das legislações aprovadas (EC 95/2016; Portaria CIT 3588/2017; Portaria Conad 1; Resolução CIT 32; Nota Técnica 11/2019; e projeto de lei retomado - PL 7.419/2006), e identificar elementos transformadores da política anterior, as ações de desmonte, efetuadas pelo Estado, na política de saúde e no campo de saúde mental, álcool e outras drogas. Parte-se do pressuposto de que as conquistas das lutas sociais pela saúde universal e pela abordagem antimanicomial são ameaçadas, em uma lógica de retrocesso e perda de direitos sociais.

\section{Estado capitalista e a importância das lutas travadas na consolidação das políticas sociais}

As conjunturas política, econômica e social atuais nos dão elementos importantes para sustentar a afirmação de que o Estado é essencial ao modo de produção capitalista. Com todos os seus instrumentos (tanto os ideológicos quanto os repressivos), o Estado brasileiro caminha de acordo com os ditames do capitalismo globalizado. Nesse sentido, a análise do Estado mostra-se essencial para a compreensão da conjuntura atual das políticas sociais brasileiras.

A abordagem de Estado, neste artigo, é aquela tratada por Poulantzas (1985), que caminha ao lado das teorias lançadas por Marx e Gramsci. Desse modo, compreende-se o Estado como uma relação de forças entre classes e frações de classe, e reafirma-o como campo contraditório de interesses, sendo assim complacente à perspectiva de que a história da luta de classes é que determina o Estado (MARX; ENGELS, 2014).

A concepção maniqueísta utilizada por alguns autores marxistas, de que o Estado é apenas o comitê executivo da burguesia, é contestada. O papel do Estado, segundo Poulantzas (1985), não se limita à repressão ou somente à ideologia, mas tem papel específico na organização das relações ideológicas e da ideologia dominante. Ou seja, o Estado é que contribui para dizer quem são as classes dominantes e dominadas, como também legaliza essa relação de subordinação.

Entretanto, o Estado não é imutável, pois compreende um movimento dialético em suas bases de sustentação. A depender da conjuntura, a depender das lutas sociais (cujo papel é fundamental) e de quem está no poder, a forma e essência desse Estado, bem como as respostas dadas por ele, vão se diferenciar. A história de nosso País, até mesmo a mais recente, nos prova isso, de modo que vivemos ditaduras, desenvolvimentismo, governos de direita, um governo mais à esquerda (porém, nem tanto) e hoje vivenciamos uma democracia ameaçada pelo fascismo. Nessas diferentes conjunturas, as políticas sociais se modificaram, atravessando, em um movimento não linear, a filantropia, caridade; noção de direitos, de cidadania; a perda de direitos, dentre outros.

Argum., Vitória, v. 11, n. 3, p. 47-66, set./dez. 2019. | ISSN 2176-9575 
Diante desse movimento dialético, vão se formando, deformando e se extinguindo, políticas, programas, leis e morais. O papel da lei proposta pelo Estado é também um motor fundamental para a garantia do sistema. É claro que, dentro do modo de produção capitalista, também há uma correlação de forças e contradições. Assim, segundo Poulantzas (1985, p. 86), "toda forma estatal, mesmo a mais sanguinária, edificou-se sempre como organização jurídica e representou-se no direito”. Desse modo, o Estado organizador representa uma orientação histórica; designa-lhe objetivo e traça o que vem a ser uma via (POULANTZAS, 1985) das consequências do que o próprio capitalismo constrói, para responder à questão social instituída.

Dessa forma, o Estado, utilizando leis e outros aparelhos, reafirma-se como organizador dessas relações capitalistas e instaura um sistema de coesão e homogeneização. Entretanto, como antes dito, compreendendo o Estado como uma relação, as lutas estabelecidas pela classe trabalhadora podem configurar uma conquista para essa classe, por meio das leis como, por exemplo, a legislação trabalhista, que hoje também é desmantelada pelo Estado. Nesse sentido:

Toda uma série de medidas econômicas do Estado, muito particularmente as que se referem à reprodução ampliada da força de trabalho, lhe foram impostas pela luta das classes dominadas em torno do que se pode designar sob a noção, social e historicamente determinada, de 'necessidades' populares: da segurança social à política relativa ao desemprego e ao conjunto de domínios assinalados do consumo coletivo [...] Se isso mostra que não se trata então de 'puras' medidas sociais de um Estado-Providência, mostra também outra coisa: não existem também, de uma parte, funções do Estado a favor das massas populares, impostas por elas, de outra parte funções econômicas a favor do capital. Todas as disposições tomadas pelo Estado capitalista, mesmo impostas pelas massas populares, são finalmente e a longo prazo inseridas numa estratégia em favor do capital ou compatível com sua reprodução ampliada. (POULANTZAS, 1985, p. 214, grifos do autor).

Ainda nessa direção, Harvey (2006) enfatiza que o Estado e, em particular, o sistema legal, têm papel crucial para a sustentação e mobilidade das relações capitalistas. $\mathrm{O}$ Estado e suas normas, aqui, se mostram indispensáveis ao funcionamento do sistema, que lucra imensamente com a institucionalização de sujeitos, como é o caso de pessoas com transtorno mental. Poulantzas (1985) dá uma contribuição, ao fazer a seguinte reflexão a respeito das normas:

O controle social organizado pelas normas gerais universais, registrando a culpabilidade dos atos e dissociando os sujeitos legais dos fora da lei, liga-se a uma regulamentação individualizada, calcada na 'mentalidade' de cada membro de um corpo social considerado como globalmente suspeito, potencialmente culpável. O confinamento geral dos fora da lei nos lugares de concentração (prisões, asilos, etc.) circunscritos, em sua materialidade, pelas normas universais de sanções e penas, articula-se ao enquadramento da população em circuitos multiformes e difusos na trama social, por procedimentos policialadministrativos, adaptados às particularidades de cada categoria de suspeitos (POULANTZAS, 1985, p. 253-254, grifos do autor).

Por conseguinte, tudo isso dá suporte para contestar uma afirmação, tão cara às classes dominantes, de que o Estado é, ou deve ser, neutro, e de que prima pelo bem-estar de

Argum., Vitória, v. 11, n. 3, p. 47-66, set./dez. 2019. | ISSN 2176-9575 
todos. De acordo com Poulanzas (1985), a partir dessa ideia de neutralidade materializada é que o Estado oculta das classes populares o seu real conteúdo de classe. Desse modo, não pode ser visto como apenas o comitê executivo da burguesia, algo que Marx (2011) já havia desconstruído em suas obras, principalmente em A Guerra Civil na França, em que desmistifica essa condição, de modo que, segundo Harvey (2006), não separa a superestrutura da base econômica, pelo contrário, seu método revela uma interação dialética entre ambas.

A contradição e a correlação de forças, que se dão a partir das lutas sociais, reafirmam a posição do Estado como relação, como campo de disputa. Entretanto, a disputa pelo Estado só é necessária porque o mesmo está veementemente a favor da classe dominante, a qual detém o seu controle. Nesse sentido, a classe dirigente tem os reconhecimentos cultural e ideológico, e detém o poder da mídia, da política e de outros espaços de poder.

Para além disso, Mandel (1982) também fornece elementos teóricos concretos a respeito das funções do Estado no capitalismo tardio, compreendido a partir da segunda fase do capitalismo monopolista (que tem como marcos a automação, o capital financeiro e a intervenção do Estado social). Para esse autor, as funções do Estado se resumem em criar condições gerais para a produção que a atividade privada não pode assegurar; reprimir qualquer ameaça das classes dominadas; e integrar as classes dominadas para que aceitem a sua condição (MANDEL, 1982). Essas funções e suas funcionalidades para o capitalismo são facilmente observadas, atualmente.

O Estado, com todo o seu aparato, tem mantido a população silenciada, seja por meio da repressão, durante as manifestações populares, seja pela alienação no trabalho e na educação, seja pelas condições de miserabilidade em que os sujeitos se encontram, seja pela forma como a chamada classe média se encontra (de forma confortável e sentindose parte da elite). Além disso, concordando com Poulantzas (1985), a relação do Estado com os meios de produção faz com que os recursos materiais de que dispõe sejam estruturalmente limitados, resultando no sucateamento dos serviços oferecidos à população, ao passo que continua salvando o capital financeiro. Nesse sentido:

As aparelhagens institucionais da saúde (segurança social, medicina, hospitais, asilos), da assistência social, do urbanismo, dos equipamentos coletivos, do lazer, são marcados com o selo burguês. Essas medidas influem na reprodução capitalista da força de trabalho e na divisão social do trabalho, mesmo se sua existência é devida, por um lado, às lutas populares e representa, às vezes, uma vitória (POULANTZAS, 1985, p. 219, grifo do autor).

Dessa forma, reitera-se a compreensão do Estado como campo contraditório de interesses, como campo de disputa, bem como a importância das lutas sociais para dominá-lo. Nessa linha, observa-se que o Estado faz concessões à classe trabalhadora mediante suas lutas, entretanto, isso se dá desde que não interfira substancialmente nas bases de sustentação do sistema. Portanto, os benefícios conquistados pela classe trabalhadora não podem ir além dos limites determinados, visto que podem comprometer gravemente o processo de reprodução do capital (POULANTZAS, 1985).

Argum., Vitória, v. 11, n. 3, p. 47-66, set./dez. 2019. | ISSN 2176-9575 
Ademais, o Estado não é uma coisa. Para o seu funcionamento, bem como do modo de produção capitalista, necessita de bases ideológicas e culturais para a sua sustentação. O modo de produção e acumulação atualmente conhecido passou por várias ressignificações, ao longo de seu processo, como pelo escravismo, liberalismo e neoliberalismo. Entende-se a história como em movimento constante e a partir das particularidades sócio-históricas do Brasil, é necessário compreender o movimento atual.

De modo mais geral, observa-se no capitalismo, hoje, a ascensão de uma extrema direita, como é a icônica eleição de Trump, nos Estados Unidos da América (EUA), forte potência mundial que interfere diretamente em nossa política; e, no Brasil, de Jair Bolsonaro. Atualmente, o movimento de contrarreforma que vem acontecendo no Brasil se dá por um novo movimento, sendo ele é nominado de nova direita ${ }^{2}$.

Diante desse entendimento, do Estado como campo de disputa, a luta travada por trabalhadores foi e é fundamental para a proteção social baseada em direito, por meio das políticas sociais, ainda que diante de uma democracia limitada e restrita à formalidade. Para Vieira (2007), “[...] a política social, compreendida como estratégia governamental de intervenção nas relações sociais, unicamente pôde existir com o surgimento dos movimentos populares do século XIX” (VIEIRA, 2007, p. 141).

No Brasil, tivemos momentos efervescentes na luta e nas conquistas de direitos, como é o exemplo da década de 1980, com a consolidação do SUS, bem como da Constituição Cidadã de 1988. Desse modo, os direitos sociais significam a consagração regulamentada das reivindicações da população.

Entretanto, para a real compreensão das políticas sociais, faz-se necessário entender a sua multideterminação. Também concordando com Vieira (2007), as políticas sociais estão associadas às políticas econômicas, e não podem ser analisadas à parte. $O$ principal ponto de convergência entre elas é que ambas estão imersas e vinculadas ao modo de produção capitalista.

Todavia, “[...] tem-se assistido na evolução do capitalismo ao predomínio da política econômica sobre a política social" (VIEIRA, 2007, p.144). Partindo dessa afirmação, chega-se à análise das nossas atuais condições econômica, política e social, que interferem diretamente nas características de nossas políticas sociais.

Com os governos Lula e Dilma, foram observados avanços nas políticas sociais, com considerável ampliação no acesso a serviços públicos; na garantia de uma renda mínima; na diminuição da pobreza em si; no acesso à universidade, dentre outras conquistas, mas ainda não descolados de uma política econômica voltada ao capital, com privatizações e parcerias de base neoliberal.

${ }_{2}^{2}$ Trata-se de uma linha política e ideológica em que se unem as vertentes do neoliberalismo com o neoconservadorismo.

Argum., Vitória, v. 11, n. 3, p. 47-66, set./dez. 2019. | ISSN 2176-9575 
Destarte, pode-se afirmar que a conjuntura ficou marcada pela essência do chamado Estado Social, à luz de Gough (1978), ou seja, fica nítida a sua característica contraditória, não somente como oferta de serviços sociais a quem necessita, mas também como Estado regulador do setor privado, que interferiu e vem interferindo diretamente na vida da população, fato que se observará nos tópicos seguintes a respeito da regulação do Estado no setor privado de saúde.

No ano de 2016, com o golpe no governo Dilma e ascensão de Temer, observam-se retrocessos catastróficos, no campo das políticas sociais. Em dois anos, o Brasil manteve uma agenda nitidamente neoliberal e neoconservadora, caracterizada por ajuste fiscal, enxugamento da máquina pública e redirecionamento do fundo público para o capital, criando o que Harvey (2008) chama de paradoxo, pois o projeto neoliberal requer um Estado não intervencionista, mas, nas mãos das elites, há intensas intervenções estatais.

Os atuais desmontes neoliberais fazem parte da agenda do capital financeiro internacional, que tem influência direta sobre os países chamados de Terceiro Mundo. Nesse sentido, "[...] o triunfo dos mercados é inconcebível sem a ativa intervenção das instâncias políticas dos Estados Nacionais, no lastro dos tratados internacionais" (IAMAMOTO, 2008, p. 25).

Dessa forma, é possível relacionar o quadro atual das políticas sociais nacionais com as orientações de organismos internacionais, que são baseadas no capital, que hoje é mundializado. Chesnais (2009) defende que, para que o mercado triunfe, são necessárias as intervenções políticas das instâncias capitalistas mais poderosas (como os EUA). Logo, vivemos atualmente sob os ditames do capital internacional, com plena liberdade de ação de organismos internacionais (CHESNAIS, 2009), como o Fundo Monetário Internacional (FMI), o Banco Mundial e, no caso da saúde, a Organização Mundial de Saúde (OMS), por exemplo. Nesse sentido é que observamos a canalização do Fundo Público para o mercado financeiro. Segundo Iamamoto (2008), na raiz do atual perfil assumido pela questão social, encontram-se as políticas governamentais favorecedoras da esfera financeira e do grande capital produtivo.

O Banco Mundial, por exemplo, emitiu relatórios que buscaram reorientar o campo da política social no Brasil. Nessas bases, observa-se a tendência da mercantilização pela privatização e desresponsabilização do Estado pelas políticas sociais. Aqui, especialmente no que tange à política de saúde, o Banco fez críticas ao seu caráter universal. A tendência, de acordo com Correia (2007), "[...] é a disseminação de 'auto ajuda' ou 'ajuda mútua', do voluntariado, do solidarismo e da filantropia” (CORREIA, 2007, p. 5). Nesse sentido, a semelhança não é mera coincidência. Como se observará a seguir, a política de saúde caminha para sua privatização, gerando a polarização no acesso. Ou seja, existe uma tendência para a geração de planos de saúde populares (proposta do $1^{\underline{0}}$ Fórum Brasil - Agenda da Saúde, de 10 de abril de 2018) e da utilização do SUS pelos pobres que não tiverem como arcar com os planos.

A pauta das políticas sociais, no Estado capitalista atual, referenciada pelo capitalismo financeirizado, se dá pela mercantilização, e abre espaços para o capital privado, para quem pode pagar e, para a outra grande massa, a tendência é a prestação desses serviços

Argum., Vitória, v. 11, n. 3, p. 47-66, set./dez. 2019. | ISSN 2176-9575 
pela chamada sociedade civil, ou, melhor, terceiro setor, por meio de Organizações Sociais (OS). Essa tendência permeia a política de saúde e o campo da saúde mental, álcool e outras drogas, desmontando o conjunto de direitos conquistado mediante muita luta.

\section{A contrarreforma do SUS: a agenda governamental de desmonte do sistema}

Após a análise do Estado atual, em que se reconhece a ascensão de uma nova direita, no Brasil, bem como apontadas as características das políticas sociais no capitalismo, consideremos agora a política de saúde, que vem correspondendo também a essa perspectiva.

O SUS foi consolidado após um longo processo de atuação dos movimentos sociais e da sociedade pelo direito à saúde pública, que enfatizou a correlação de forças e as lutas sociais como aspectos centrais para o direcionamento das políticas tomadas pelo Estado, como explicitado no tópico anterior. Para a consolidação da saúde como um direito, foi necessário um movimento amplo e organizado, conhecido como Reforma Sanitária. A democratização da saúde como parte da democratização da vida social, do Estado e dos seus aparelhos, foi defendida durante o enfrentamento da ditadura (PAIM, 2009), correspondendo a um embate entre ideias, propostas e perspectivas extremamente antagônicas.

A Reforma Sanitária surge como ideia e crítica aos limites da medicina preventiva, ao mesmo tempo em que busca alternativas para a crise da saúde durante o autoritarismo (PAIM, 2009). Naquele momento, Bravo (2006) ressalta que houve um aumento da medicina previdenciária e um privilegiamento de setores privados, demonstrando uma lógica de saúde como mercadoria.

O movimento teve enorme relevância e influência na consolidação da Constituição Federal de 1988, após a 8a Conferência Nacional de Saúde, ocorrida em 1986, que levantou a bandeira da saúde como direito, o financiamento setorial e a reformulação do Sistema Nacional de Saúde (BRAVO, 2006). Após a conferência, a Assembleia Nacional Constituinte também representou um marco na consolidação do SUS, visto que o setor de saúde levou as propostas expressas hoje na Constituição Federal de 1988. No documento, a saúde é expressa como direito de todos e dever do Estado (BRASIL, CF de 1988). Também se expressa o caráter suplementar da iniciativa privada. Entretanto, atualmente, observamos a alternância dessa perspectiva, pois o Estado redireciona a sua responsabilidade ao setor privado.

Interesses políticos e econômicos estão por trás de tal redirecionamento. Como foi dito, o caráter conjuntural do País, mais especificamente da governança, interfere diretamente no formato das políticas. A conjuntura brasileira, neste momento, não favorece a população. Não obstante, esse movimento não é recente, de modo que Paim (2009) já havia enfatizado que os governos do período pós-constituinte (Itamar Franco, Fernando Henrique Cardoso e Luiz Ignácio Lula da Silva ) não fizeram avançar o processo da Reforma Sanitária. Concordando com o autor, percebe-se que tal estagnação também foi mantida em governos posteriores, como nos mandatos de Dilma e no

Argum., Vitória, v. 11, n. 3, p. 47-66, set./dez. 2019. | ISSN 2176-9575 
assumido por Temer, e tem perspectiva de continuidade e ainda mais retrocesso no governo de Jair Bolsonaro, dadas as declarações que tendem a exaltar o setor privado e a descontinuidade do financiamento contida na Emenda à Constituição (EC) 95.

Nesse sentido, o Estado, cada vez mais, vem destinando recursos e favorecendo interesses privados, assim como Harvey (2008) explicita, ao alegar que as decisões legais, de um Estado neoliberal, tendem a favorecer direitos privados e a obtenção de lucro, em detrimento dos direitos à igualdade e justiça social. Quando se questiona sobre o que está por trás de determinada política, as respostas são preocupantes. Na última campanha eleitoral, segundo dados do Tribunal Superior Eleitoral, também analisados por Lima (2018), foram doados $\mathrm{R} \$ 54,9$ milhões, por empresas de planos privados de saúde e de grandes hospitais privados, a campanhas eleitorais, cuja consequência foi a eleição de três senadores, trinta deputados federais e, não coincidentemente, do ministro da saúde de Temer, Ricardo Barros.

Tais interesses privados, portanto, ancorados nas recomendações internacionais, como elucidado no tópico anterior, corroboram a privatização do setor e o desmonte da perspectiva de universalidade do acesso à saúde por meio do Estado.

O desmonte em curso, não só do SUS, mas também de outras políticas, revela a já lembrada função do Estado. Dessa forma, a conjuntura reafirma o papel do Estado a favor do capital, em seu sentido funcional.

O Estado deve se empenhar, quando necessário, em remover as barreiras em favor da mobilidade. Em geral, o Estado e, em particular, o sistema legal possuem um papel crucial a desempenhar na sustentação e na garantia da estabilidade desses relacionamentos básicos (HARVEY, 2006, p. 84).

O Estado, portanto, tem legitimado a perspectiva privatizante, por meio, inclusive, de instrumentos legais, ou seja, de legislações que viabilizam o desmonte do sistema público e universal. Podemos citar, principalmente, a EC 95, que institui o novo regime fiscal e, em poucas palavras, congela os gastos da saúde por duas décadas.

Desse modo, não é difícil imaginar como estará o serviço público até lá. Aproveitando esse sucateamento, juntam-se ao movimento as propostas mercadológicas de Planos de Saúde Populares, em que a cobertura é bastante limitada. Em 10 de abril de 2018, ocorreu o I Fórum Brasil agenda da saúde, com o slogan "ousadia de propor um novo sistema de saúde”. De acordo com a proposta, lançada pela Federação Brasileira de Planos de Saúde, $50 \%$ da população teria acesso ao SUS, orientado para os mais pobres, e 50\% pagaria planos de saúde. A perspectiva adotada por essa proposta reitera as análises de Paim (2018) de que o intuito não é a extinção do SUS, pois tem sido benéfico e orgânico aos interesses capitalistas, mas a sua redução aos setores mais empobrecidos da sociedade, retirando o seu caráter universal, previsto constitucionalmente.

Retoma-se, também, um projeto de mudanças dos Planos de Saúde (o PL 7.419/2006), que os torna ainda mais lucrativos. Perfila-se, em consequência, um divórcio crescente entre Estado e as classes subalternas (IAMAMOTO, 2008). 
Nessa direção, é atribuído o termo contrarreforma, quando Coutinho (2012) enfatiza que não é o momento do novo, mas precisamente do velho, retomando a assistência médica utilizada anteriormente, ou seja, realizada por meio de ações filantrópicas para aqueles que não podiam pagar e pela prática liberal para a parcela mais abastada (LIMA, 2018).

Considerado esse contexto, enfatiza-se que o projeto neoliberal vem fazendo parte da agenda brasileira de maneira sistemática e não há dúvidas de que a sua função vem sendo alcançada eficazmente, ou seja, concordando com Harvey (2008), o neoliberalismo vem restaurando o poder de classe, tanto nas bases econômicas quanto políticas.

A correlação de forças é essencial para o privilegiamento de interesses. Os espaços destinados ao controle social, construídos também a partir do Movimento de Reforma Sanitária, são importantes nesse cenário. Paim (2009) destaca que, apesar do retraimento dos movimentos sociais, esses espaços, concretizados pelos conselhos e conferências de saúde, permitiam a constituição de novos atores políticos e possibilitaram a continuidade do processo da reforma. Destarte, tais mecanismos deveriam ser fortalecidos pela sociedade, de modo que as contrarreformas vêm sendo instituídas sem a devida discussão, de forma arbitrária ou, até mesmo, com o aval dos próprios conselhos, como é o caso da política de saúde mental com a questão das drogas, como se verá adiante.

Um ponto importante a ser discutido, também enfatizado por Paim (2009), é a redução do movimento da Reforma Sanitária ao SUS, ou seja, a questão a ser enfrentada é muito mais ampla. A Reforma Sanitária deve ter como norte a sua determinação social, de maneira mais ampla. Não basta apenas lutar contra os desmontes no SUS e nos seus serviços, mas ter em vista que tais desmontes são parte de uma agenda do capital de caráter mais estrutural.

\section{Os impactos das contrarreformas na política de saúde mental, álcool e outras drogas: um retrocesso da luta antimanicomial}

Na saúde mental, a onda neoliberal e, vale dizer, neoconservadora, tem força avassaladora. Desde 2015, a política que vinha sendo construída desde a Reforma Psiquiátrica, nas décadas de 1970 e 1980, vem sendo cada vez mais desmontada.

No Brasil, o movimento da Reforma Psiquiátrica é registrado a partir de 1970, e a lei que dispõe sobre a proteção de pessoas com transtornos mentais é criada apenas em 2001. $\mathrm{O}$ tratamento, após a reforma, tende a ser estabelecido de forma mais humana, constituindo, um de seus pilares, a desinstitucionalização. Assim, o movimento de Reforma Psiquiátrica brasileira buscou a desconstrução da realidade manicomial e a construção de novas realidades, segundo novas bases políticas e sociais, operando transformações de uma cultura sustentada pela violência, discriminação e aprisionamento da loucura (AMORIM; DIMENSTEIN, 2009).

Dessa forma, coloca-se o tema da cidadania no centro do debate sobre a violência asilar e sua superação (DELGADO, 1992) e a Reforma Psiquiátrica trouxe mudanças

Argum., Vitória, v. 11, n. 3, p. 47-66, set./dez. 2019. | ISSN 2176-9575 
importantes de práticas, saberes, valores culturais e sociais, nas instituições de saúde mental, e compreendeu um movimento social pelos direitos dos pacientes psiquiátricos, formado por trabalhadores do movimento sanitário, associações de familiares, sindicalistas e pessoas com longo histórico de internações psiquiátricas, a partir de um movimento de luta antimanicomial que perdura até os dias atuais.

A Reforma Psiquiátrica, em suma, chamou o campo da saúde mental a refazer-se por inteiro, ampliando o seu foco de abordagem e procurando romper com as delimitações dos saberes tradicionais na área (VASCONCELOS, 2002). Saberes esses que aprisionavam pessoas, utilizando-se da tortura e do isolamento como formas de higiene social. Como resultado do processo de reforma, foi construída uma política mais humanizada, com base em legislações, como a Lei 10.216/2001, que regulam uma série de direitos humanos e sociais de pessoas com transtornos mentais, além de uma rede substitutiva aos manicômios, ofertada pelo Estado, localizada dentro da Rede de Atenção Psicossocial (Raps).

Não obstante, a contrarreforma do Estado, que está em curso em várias políticas sociais, vem causando a reestruturações dessa perspectiva antimanicomial. Nesse setor, além da mercantilização da saúde e desresponsabilização total do Estado, a população usuária traz o estigma da marginalização da sociedade. Vale ressaltar que as contrarreformas no campo da saúde mental, álcool e outras drogas vêm sendo consolidadas a partir de um novo marco legal que, em suma, resgata a lógica manicomial e de violação de direitos. Amarante e Nunes (2018) ressaltam que esse movimento não é assim tão recente. Segundo o autor, desde 2015, ainda no governo de Dilma Roussef, quando um ex-diretor de um dos maiores hospitais psiquiátricos da América Latina - fechado pelo Ministério Público - foi nomeado para a coordenação da política de saúde mental, álcool e outras drogas, o modelo manicomial passou a ganhar espaço novamente. De forma mais ampla, desde meados dos anos 1990, o desmonte das políticas sociais e da política de saúde mental, especificamente, está em curso, devido à hegemonia do neoliberalismo, principalmente no que tange à diminuição do investimento público (BISNETO, 2007). Desde o governo Michel Temer, em 2016, esse modelo vem sendo consolidado.

A partir das novas legislações, que serão tratadas adiante, o Estado reconhece a sua ineficiência no atendimento dessas demandas. Vale ressaltar que essa ineficiência é proposital, pois considera o atendimento aos interesses privados, como relatado anteriormente. Direciona, nesse sentido, o papel da proteção às Organizações Não Governamentais (ONGs), CTs e para o que foi pauta de luta do movimento de Reforma Psiquiátrica, ou seja, os hospitais psiquiátricos (popularmente chamados de manicômios).

A contrarreforma vem se instituindo legalmente pelo Estado. Além da EC 95, conhecida como a PEC do fim do mundo, já no final de 2017 e início de 2018, foram publicadas normas para a reorientação da política de saúde mental, álcool e outras drogas. São elas:

- Resolução CIT 32/2017 - prevê o fortalecimento da Raps; 
- Portaria CIT 3.588/2017 - interrompe o fechamento de leitos em hospitais psiquiátricos; amplia valores pagos para a internação; e prevê a expansão do financiamento público às CTs (BRASIL, 2017);

- Portaria Conad 1/2018b - também desmonta direitos conquistados, os quais serão objetos de debate mais à frente (BRASIL, 2018b).

Já em 2019, na gestão governamental de Jair Bolsonaro, a nova política está sendo consolidada. A Nota Técnica MS 11/2019 visa a esclarecer as mudanças estabelecidas e traz um cenário catastrófico de retrocesso, reforçando a inserção das CTs e de hospitais psiquiátricos formalmente na rede e retomando, por exemplo, o uso da eletroconvulsoterapia como tratamento, que foi símbolo de violência na conjuntura manicomial e ainda é permeada pelo estigma.

Além disso, segundo a nota: "O Ministério da Saúde não considera mais serviços como sendo substitutos de outros, não fomentando mais fechamento de unidades de qualquer natureza. A Rede deve ser harmônica e complementar" (BRASIL, 2019). Tal perspectiva quebra com um histórico tão caro ao movimento de Reforma Psiquiátrica, que, como dito no início deste tópico, teve como pauta o fechamento desses leitos e, como avanço, a construção de uma rede substitutiva (AMARANTE; NUNES, 2018; VASCONCELOS, 2002).

Forma-se, assim, uma rede de (des)proteção de parceria público-privada pautada pela institucionalização. Importante enfatizar a destinação, em 2018, por parte do governo federal, de $\mathrm{R} \$ 87$ milhões às CTs, um crescimento de $100 \%$ no volume de recursos (BRASIL, 2018a).

Assim, fica explícito que os governantes estão interessados em repassar o dinheiro público para os empresários do setor psiquiátrico e terceiro setor filantrópicos, enriquecendo, dessa forma, a burguesia e outros setores conservadores, que compõem a base de sustentação de seus mandatos (BISNETO, 2007).

Um ponto importante a ser tratado é a peculiaridade dessa contrarreforma. Nota-se que não é uma medida puramente neoliberal, visto que o neoconservadorismo está fortemente caracterizado. Trata-se de uma contrarreforma imersa em uma hegemonia da nova direita, que une as duas concepções antagônicas: neoconservadorismo e neoliberalismo (PEREIRA, 2016). Desse modo, de um lado, lucra-se imensamente com a loucura, ou com a dependência química, a partir das internações e, no caso da política de drogas, com a ilicitude; e, de outro, a moralização dessas questões, numa perspectiva de higiene social, é legitimada pelo neoconservarismo, potencializando os lucros e violando direitos.

O caráter conservador, ainda no governo Michel Temer, é demonstrado nessa reorientação catastrófica. Em entrevista à Agência Brasil, o ministro, à época, Ricardo Barros enfatizou: 
diretamente.' Além disso, Barros disse que a ação que essas instituições, 'especialmente as igrejas de todas as ordens, fazem com a família e o drogado realmente é fundamental para que haja sucesso na permanência dessa pessoa como recuperado' (MARTINS, 2017, não paginado, grifos do autor).

Essa contrarreforma da política, além de ser um retrocesso de direitos de cidadania, é um retrocesso dos direitos humanos. Basaglia (1985) ressalta que pode ocorrer, na comunidade terapêutica, a reprodução dos esquemas de exclusão social considerados característicos do manicômio, com a atuação de setores programaticamente fechados (privando o paciente da liberdade de movimento, retiram-lhe a possibilidade de realizar opções primárias).

A natureza das CTs foi tema de pesquisa do Instituto de Pesquisa Aplicada (Ipea), no ano de 2017. Segundo os seus resultados:

O modelo de cuidado proposto pelas CTs ancora-se em três pilares - a saber, trabalho, disciplina e espiritualidade [...] O exercício do trabalho é entendido como terapêutico (laborterapia), consistindo tanto das tarefas de manutenção da própria comunidade, como de atividades produtivas e de geração de renda. Dele espera-se o benefício da aquisição de autodisciplina e autocontrole, disposições entendidas como ausentes entre as pessoas que fazem uso problemático de SPAs, mas necessárias para o seu sucesso na vida social. As práticas espirituais, por sua vez - levadas a efeito com ou sem o apoio de igrejas e organizações religiosas -, buscam promover a fé dos internos em um ser ou instância superior, vista como recurso indispensável, seja para o apaziguamento das dores e sofrimentos dos indivíduos, seja para o seu enquadramento moral (INSTITUTO DE PESQUISA ECONÔMICA APLICADA, 2017, p. 8).

A lógica prevista e tida como terapêutica das CTs, desse modo, não garante direitos, nem um tratamento efetivo para essa população. A causa da condição do usuário é explicada por meio da culpabilização do indivíduo, visto como desajustado, buscando assim "[...] operar uma reforma moral dos sujeitos, que os conduzam a uma reinvenção de si" (INSTITUTO DE PESQUISA ECONÔMICA APLICADA, 2017, p. 9).

Durante o lançamento da frente parlamentar pela nova política de saúde mental, álcool e outras drogas, no dia 27 de novembro de 2018, a população de usuários e profissionais dos Centros de Atenção Psicossocial (Caps), não teve voz, demonstrando um bloqueio no que se refere à participação social e política. Tudo isso no que deveria ser a casa do povo, a Câmara dos Deputados. Ainda nesse evento, ficaram nítidos os interesses por trás da contrarreforma proposta. O documento apresentado na sessão foi construído pela Federação Brasileira de Hospitais, "uma das maiores representantes da rede de saúde privada do País"3.

Outro ponto importante a ser destacado, e que enfatiza a institucionalização como ferramenta, é a reabertura de leitos psiquiátricos. Com muita dificuldade e por meio do

3Ainda de acordo com informações disponíveis no site, “[...] a proposta da Federação Brasileira de Hospitais é fortalecer a posição institucional da entidade frente às negociações da rede particular de saúde com o poder público e as operadoras de Planos de Saúde, com o propósito de promover um plano para recuperação por meio da atualização dos valores pagos às unidades conveniadas ao SUS e ao sistema suplementar" (Ver FEDERAÇÃO BRASILEIRA DE HOSPITAIS, [201-].

Argum., Vitória, v. 11, n. 3, p. 47-66, set./dez. 2019. | ISSN 2176-9575 
movimento de Reforma Psiquiátrica, caminhava-se para o fechamento desses leitos, entendendo que o tratamento direcionado aos usuários deve ser contrário à institucionalização, em meios ambulatoriais, e esvaziado de uma lógica centrada na doença, loucura e medicalização.

A entrevista realizada pela Agência Brasil com o coordenador nacional de saúde mental, álcool e outras drogas, Quirino Cordeiro, no governo Temer e, atualmente, secretário nacional de Cuidados e Prevenção às Drogas, do Ministério da Cidadania, no governo Bolsonaro, demonstra, por si só, a concepção sobre saúde mental de nossos representantes:

Quirino Cordeiro disse que o ministério tem o objetivo de ampliar a taxa de ocupação dos leitos dedicados às pessoas com problemas mentais em hospitais gerais. Hoje, ela é de menos de $20 \%$. A meta é chegar a $80 \%$ de ocupação. 'Para não estimular novos moradores, no caso de internações que ultrapassarem mais de 90 dias, a diária cairá metade do preço', detalhou Cordeiro (MARTINS, 2017, não paginado).

Para completar a agenda de desmonte das políticas de saúde mental, a pauta sobre as drogas, que também compõe a política, se faz em um forte retrocesso às conquistas relativas à descriminalização, à desresponsabilização do indivíduo e da redução de danos. O Conad publicou uma resolução, em 2018, que reorienta a política. Segundo a resolução, as principais mudanças são:

- Posição contrária à legalização das Drogas;

- Estratégias de tratamento não devem se basear apenas em Redução de Danos, mas também em ações de Promoção de Abstinência, Suporte Social e Promoção da Saúde;

- Apoio aos pacientes e familiares em articulação com Grupos, Associações e Entidades da Sociedade Civil, incluindo as Comunidades Terapêuticas; (BRASIL, 2018a, não paginado, grifos nossos).

Em abril de 2019, o Presidente Jair Bolsonaro consolidou a perspectiva do tratamento mediante o uso da abstinência, assinando um decreto ${ }^{4}$ que extingue o uso da redução de danos como forma de tratamento, mecanismo este considerado um avanço, pois é utilizado por países que são referência, como Holanda e Inglaterra, e vinha promovendo resultados positivos, dentro dos Caps.

Dessa forma, como afirma Coutinho (2012), a principal característica das contrarreformas, como as presenciadas atualmente, é que a luta de classes continua a existir, entretanto, "[...] não se trava mais em nome da conquista de novos direitos, mas da defesa daqueles já conquistados no passado” (COUTINHO, 2012, p. 123).

É evidente o tamanho do gasto público com a privatização, ou seja, não é a falta de orçamento que caracteriza as mudanças, mas justamente a perspectiva mercantilizadora da saúde pública com o redirecionamento do fundo público. Essa

4 No momento em que este artigo foi escrito, o decreto ainda estava sendo encaminhado para publicação no Diário Oficial da União.

Argum., Vitória, v. 11, n. 3, p. 47-66, set./dez. 2019. | ISSN 2176-9575 
questão também é analisada por Iamamoto (2008), ao afirmar que uma das características do capitalismo financeiro, ou seja, no Estado reduzido, o fundo público passa a ser canalizado para alimentar o mercado financeiro.

O Estado, nesse sentido, passa a fazer o que Lima (2018) chama de administração gerencial, ou seja, a gestão fica com os setores privados, enquanto que o repasse de verbas continua sendo do setor público. Como afirma Lima (2018), essas parcerias acontecem no âmbito do livre jogo do mercado, predominando a dinâmica de redução de direitos, e transformando-os em mercadoria.

\section{Conclusão}

O estudo qualitativo, a partir de levantamento bibliográfico, demonstrou que a contrarreforma na política de saúde, e no campo de saúde mental, álcool e outras drogas, no Brasil, vem correspondendo aos ditames do capital financeiro internacional, estando o País representado por um Estado neodireitista, atualmente ainda mais evidente, com a eleição do Presidente Jair Bolsonaro, cujas bases são sustentadas pela nova direita.

Além disso, mostrou-se que o Estado é essencial para a reprodução do capitalismo, não obstante ser um campo de disputa, em que são importantes as lutas sociais para a conquista de direitos, veementemente ameaçados por aqueles que detêm o poder. Ademais, demonstrou-se também que as políticas sociais, como as aqui especificamente evidenciadas, também são disputadas por interesses antagônicos; de um lado, a população, e, de outro, os campos privados que visam ao lucro.

Nos últimos quatro anos, vêm sendo realizadas ações de desmonte de direitos historicamente (e duramente) conquistados no campo da saúde e da saúde mental, mais explicitamente por meio dos processos de Reformas Sanitária e Psiquiátrica. Essas ações, legalmente assinadas pelo executivo e seus aliados, interferem negativamente na vida dos usuários do SUS que, vale dizer, são pobres e dependem unicamente de seus serviços.

O fato mais icônico é a aprovação da EC 95/2016, que congela os gastos com a saúde por 20 anos, o que resultará na intensificação do sucateamento dos serviços e na procura, pela população, por planos privados, que deixam grande parte dos usuários descobertos e com as necessidades desassistidas. Nesse sentido, evidencia-se que, cada vez mais, a saúde se torna mercadoria e a saúde mental, que implica também a questão de drogas, objeto de filantropia e de violação de direitos humanos, como demonstrado no decorrer do artigo.

As tendências futuras são de continuidade e intensificação dessa lógica, visto que, no dia 27 de novembro de 2018, no lançamento da frente parlamentar pela nova política de saúde mental, álcool e outras drogas, Luiz Mandetta, ministro da saúde do governo Bolsonaro, explicitou suas concepções no campo da saúde mental, as quais visam desmontar os serviços constituídos e primar pela atenção psiquiátrica manicomial e religiosa. 
Outros fatores que demonstram a continuidade dessa tendência, foi o lançamento da Nota Técnica 11/2019, que reafirma os retrocessos em curso, como a anexação das CTs e de hospitais psiquiátricos à Raps e a utilização da eletroconvulsoterapia como forma de tratamento; além da assinatura do decreto que extingue a redução de danos como forma de tratamento.

Fica evidente que o Brasil caminha na direção do retrocesso, baseado na moralização e culpabilização do indivíduo; da criminalização da pobreza e da mercantilização da saúde e da loucura, distante de uma perspectiva de direito. Diante desse contexto, a consolidação do SUS que queremos, integral, universal e de qualidade, é um desafio, atualmente. As lutas que se travaram para a sua consolidação, nas Reformas Sanitária e Psiquiátrica, mostram-se necessárias. Como evidenciado no decorrer deste artigo, as lutas sociais são essenciais para a conquista de direitos ou, como é o caso, para não os perder.

Não obstante, as lutas sociais por meio da participação social, diante da conjuntura atual, também são um desafio, de modo que os mecanismos de controle social também vêm sendo atacados pelo governo Bolsonaro. O exemplo mais concreto dessa desmobilização está no Decreto 9.759/2019, que extingue conselhos importantes na fiscalização e no controle das ações públicas em diversos setores.

Diante desse fluxo de retrocesso, além de entender o desmonte da política de saúde mental como resultado de uma totalidade, ou seja, do processo de financeirização e mundialização do capital, que tem por base a influência de organismos internacionais no direcionamento de uma agenda de desmonte de direitos, bem como o apoio do Estado a esses segmentos, podemos resumir, a partir da análise das legislações, as principais tendências atuais da política de saúde mental da seguinte maneira:

- Vive-se uma retomada da lógica manicomial, no que diz respeito aos tratamentos;

- Retorno do Estado Policial, no que diz respeito à guerra às drogas, embasado na criminalização e culpabilização individual e da não compreensão da questão como de saúde pública;

- Multiplicação de instituições religiosas e filantrópicas que, historicamente, têm promovido a violação de direitos humanos;

- O adoecimento mental crescente da sociedade, em um contexto capitalista de produção, que promove, cada vez mais, a individualização, pobreza, o desemprego, a violência, dependência química, que são fatores consequentes do contexto social. Nesse sentido, essa população terá o modelo, comprovadamente falho, como (des)proteção.

Todas essas tendências também dificultam a participação ativa da sociedade, por meio das lutas sociais, em ambientes de decisão, como também no campo das ruas e da mídia. Esse silenciamento da população é muito visado pelo Estado tratado aqui, o qual está veementemente a favor do capital. 


\section{Referências}

AMARANTE, Paulo; NUNES, Mônica de Oliveira. A reforma psiquiátrica no SUS e a luta por uma sociedade sem manicômios. Ciênc. Saúde Coletiva, Rio de Janeiro, v. 23, n. 6, p. 2067-2074, 2018.

AMORIM, Karenina de M.A.; DIMENSTEIN, Magda. Desinstitucionalização em saúde mental e práticas de cuidado no contexto do serviço residencial terapêutico. Ciênc. Saúde Coletiva, Rio de Janeiro, v. 14, n. 1, jan./fev. 2009. Disponível em: http://www.scielo.br/scielo.php?script=sci_arttext\&pid=S1413-81232009000100025 . Acesso em: 8 ago. 2018.

BASAGLIA, Franco. A instituição negada: relato de um hospital psiquiátrico. 2. ed. Rio de Janeiro: Edições Graal, 1985.

BEHRING, Elaine Rossetti. Brasil em contrarreforma: desestruturação do Estado e perda de direitos. São Paulo: Cortez, 2003.

BISNETO, José Augusto. Serviço social e saúde mental: uma análise institucional da prática. 3. ed. São Paulo: Cortez, 2007.

BRASIL. Ministério da Saúde. Nota Técnica no 11/2019-CGMAD/DAPES/SAS/MS. Esclarecimentos sobre as mudanças na Política Nacional de Saúde Mental e nas Diretrizes da Política Nacional sobre Drogas. Brasília(DF), 2019. Disponível em: http://pbpd.org.br/wp-content/uploads/2019/o2/o656ad6e.pdf. Acesso em: 10 fev. 2019 .

BRASIL. Ministério da Saúde. Política nacional de saúde mental, álcool e outras drogas. Brasília (DF), 2018a. Disponível em: http://portalms.saude.gov.br/politicanacional-de-saude-mental-alcool-e-outras-drogas. Acesso em: 8 ago. 2018.

BRASIL. Conselho Nacional de Políticas sobre Drogas. Portaria n. 1/2018. Define as diretrizes para o realinhamento e fortalecimento da Pnad. Brasília (DF), 2018b.

BRASIL. Ministério da Saúde. Portaria 3.588, de 21 de dezembro de 2017. Altera as Portarias de Consolidação n. 3 e n. 6, de 28 de setembro de 2017, para dispor sobre a Rede de Atenção Psicossocial, e dá outras providências. Brasília (DF), 2017.

BRASIL. [Constituição de 1988]. Constituição da República federativa do Brasil de 1988. Brasília (DF): Senado Federal; Centro Gráfico, 1998. 292 p.

BRAVO, Maria Inês Souza. Política de saúde no Brasil. In: MOTA, Ana Elizabete et. al. (orgs.). Serviço social e saúde: formação e trabalho profissional. Abepss/Opas, 2006.

CHESNAIS, François. Mundialización: El capital financeiro em el comando. In: BORGIANNI, Elisabete e Montaño, Carlos (orgs). Coyuntura actual, latinoamericana y mundial: tendências y movimientos. São Paulo: Cortez, 2009.

Argum., Vitória, v. 11, n. 3, p. 47-66, set./dez. 2019. | ISSN 2176-9575 
CORREIA, Maria Valéria. A Saúde no contexto da crise contemporânea do capital. O Banco Mundial e as tendências da contrarreforma na política de saúde brasileira.

Temporalis, Brasília: Abepss/Política de Saúde e Serviço Social: impasses e desafios, ano I, n.1, 2007.

COUTINHO, Carlos Nelson. A época neoliberal: revolução passiva ou contrarreforma? Novos Rumos, Marília, v. 49, n. 1, 2012.

DELGADO, Pedro Gabriel. As razões da tutela. Rio de Janeiro: Te Coroá, 1992.

FEDERAÇÃO BRASILEIRA DE HOSPITAIS. Quem somos. FBH, Sobre, Brasília, DF, [201-]. Disponível em: http://fbh.com.br/sobre/. Acesso em: 10 ago. 2018.

GOUGH, Ian. Economia politica del estado del bienestar. Traducción: Gerório Rodriguez Cabrero. Madrid: H. Blume Ediciones, 1978.

HARVEY, David. A produção capitalista do espaço. 2. ed. São Paulo: Annablume, 2006.

HARVEY, David. O neoliberalismo: história e implicações. São Paulo: Loyola, 2008.

IAMAMOTO, Marilda. Estado, classes trabalhadoras e política social no Brasil. In: BOSCHETTI et al. (org). Política social no capitalismo: tendências contemporâneas. São Paulo: Cortez, 2008.

IAMAMOTO, Marilda Vilela; CARVALHO, Raul. Relações Sociais e Serviço Social no Brasil: esboço de uma interpretação histórico-metodológica. São Paulo, Cortez, 1983.

INSTITUTO DE PESQUISA ECONÔMICA APLICADA. Perfil das comunidades terapêuticas brasileiras. Brasília (DF), mar. 2017. (Nota técnica Diest, n. 21 ). Disponível em: http://www.ipea.gov.br/portal/images/stories/PDFs/nota_tecnica/20170418_nt21.pdf. Acesso em: 23 jun. 2018.

LIMA, Joseane Barbosa de. A contrarreforma do Sistema Único de Saúde: o caso das organizações sociais. Argumentum, Vitória, v. 10, n. 1, p. 88-101, jan./abr. 2018.

MANDEL, Ernest. O capitalismo tardio. São Paulo: Abril Cultural, 1982.

MARTINS, Helena. Nova política de saúde mental favorece ampliação de comunidades terapêuticas. Agência Brasil, EBC, Brasília (DF), 27 dez. 2017. Disponível em: http://agenciabrasil.ebc.com.br/direitos-humanos/noticia/201712/nova-politica-de-saude-mental-favorecera-ampliacao-de-comunidades. Acesso em: 23 jun. 2018. 
MARX, Karl; ENGELS, Friedrich. O manifesto comunista. 3. reimpr. São Paulo: Boitempo, 2014.

MARX, Karl. A guerra civil na França. São Paulo: Boitempo, 2011.

PAIM, J. S. Sistema Único de Saúde (SUS) aos 30 anos. Ciência \& Saúde Coletiva, Rio de Janeiro, v. 23, n. 6, p. 1723-1728, 2018. Disponível em:

http://www.scielo.br/scielo.php?pid=S1413-

81232018000601723\&script=sci_abstract\&tlng=pt. Acesso em: 5 abr. 2019.

PAIM, J. S. Uma análise sobre o processo de Reforma Sanitária brasileira. Saúde em

Debate, Rio de Janeiro, v. 33, n. 38, p. 27-37, jan./abr., 2009.

PEREIRA, Camila Potyara. Proteção social no capitalismo: crítica a teorias e ideologias conflitantes. São Paulo: Cortez, 2016.

POULANTZAS, Nicos. O estado, o poder e o socialismo. 2. ed. Rio de Janeiro: Edições Graal, 1985.

VASCONCELOS, Eduardo Mourão (org). Saúde mental e serviço social: o desafio da subjetividade e da interdisciplinaridade. 2. ed. São Paulo: Cortez, 2002.

VIEIRA, Evaldo. Os direitos e a política social. São Paulo: Cortez, 2007. Cap. 5 e 6, p. 136-152.

\footnotetext{
Lara Lisboa FARIAS

Assistente Social na Empresa Brasileira de Serviços Hospitalares, com atuação na área de saúde mental. Formada pela Universidade de Brasília, em 2017. É mestranda do Programa de Pós-Graduação em Política Social da Universidade de Brasília - PPGPS. Tem como tema de pesquisa a política de saúde mental, álcool e outras drogas. Integra o grupo TRASSO (Grupo de Estudos e Pesquisas sobre Trabalho, Sociabilidade e Serviço Social). Foi bolsista pelo Observatório de Saúde Mental/ Ministério da Saúde/ FINATEC, compondo o grupo de extensão sobre processos formativos e participativos de profissionais, usuários e familiares da rede de atenção psicossocial do Distrito Federal, mediante orientação da Profł Dra. Andreia de Oliveira SER/ UnB.
} 